\title{
Uterine Perforation, CTCAE
}

National Cancer Institute

\section{Source}

National Cancer Institute. Uterine Perforation, CTCAE. NCI Thesaurus. Code C143919.

A disorder characterized by a rupture in the uterine wall. 